\title{
The influence of Australian eye banking practices on corneal graft survival
}

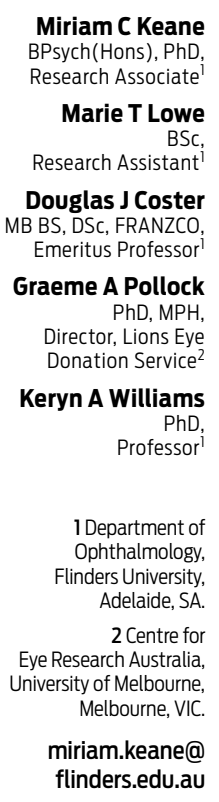

MJA 2013; 199: 275-279 doi: 10.5694/mjal2.11584 orneal transplantation enables the restoration of sight to people with corneas damaged by disease or trauma. In Australia, as in many countries, donor corneas are preserved between retrieval and transplantation in several ways and for variable periods in licensed eye banks.

It has been recommended that corneas be retrieved within 12 hours of donor death, ${ }^{1}$ but there is no consensus on the acceptable maximum interval, and this time limit is sometimes stretched. $^{2}$ In Australia, after retrieval and processing within a 24-hour period, corneas are currently preserved in an eye bank in one of three ways: in tissueculture medium at $4^{\circ} \mathrm{C}$, in organ culture at $30-37^{\circ} \mathrm{C}$, or occasionally as a whole enucleated globe in a moist pot at $4^{\circ} \mathrm{C}$. Storage time depends on the preservation method but corneas will generally be transplanted as soon as practicable, to limit the inevitable deterioration that occurs after death and during storage. ${ }^{3}$

Although Australia's five eye banks are able to collect sufficient donor tissue to meet the nation's needs, they are not located close to all transplant centres. Tasmania sources virtually all its donor tissue from the Australian mainland, and corneas may be transported between other states, and occasionally between Australia and New Zealand, to cover local shortfalls in availability or to meet an emergency demand. When surgery is performed at a distance from the cornea procurement site, the tissue is transported by air freight. Potential issues associated with transportation include the additional handling involved, variations in temperature and pressure during transit, shaking, and extended donor death-to-transplantation time. ${ }^{4-6}$

Using data from a national registry of corneal graft outcomes, we examined the impact of methods of corneal preservation and air transport on subsequent corneal graft survival.

\section{Methods}

Australian eye banks licensed by the Therapeutic Goods Administration

Objective: To identify eye banking practices that influence corneal graft survival. Design, setting and participants: Prospective cohort study of records of 19254 followed corneal grafts in 15160 patients, submitted to the Australian Corneal Graft Registry between May 1985 and July 2012.

Main outcome measures: Influence of corneal preservation method (organ culture, moist pot, Optisol, other); death-to-enucleation, death-to-preservation and enucleation-to-graft times; transportation by air; graft era; and indication for graft on probability of graft survival at most recent follow-up.

Results: In multivariate analysis, 919 penetrating grafts performed using corneas transported interstate by air exhibited worse survival than 14684 grafts performed using corneas retrieved and used locally (hazard ratio [HR], 1.44; $95 \% \mathrm{Cl}, 1.21-1.73 ; P=0.001)$. This was also the case for traditional lamellar grafts ( 64 corneas transported by air and 813 used locally; $\mathrm{HR}, 1.69 ; 95 \% \mathrm{Cl}$, 1.03-2.78; $P=0.038$ ). Indication for graft influenced survival of penetrating grafts (4611 keratoconus, 727 emergency or high-risk, 10265 other indication; global $P<0.001$ ) and traditional lamellar grafts ( 65 keratoconus, 212 emergency or high-risk, 600 other indication; global $P<0.001)$. The preservation medium in which corneas used for traditional lamellar grafts were stored exerted a marginal influence on graft survival (global $P=0.047$ ).

Conclusions: Donor corneas transported interstate exhibited poorer survival after transplantation than those retrieved and grafted locally. Higher proportions of emergency procedures involving transported corneas did not account for this difference. Where possible, efforts to avoid transportation of corneal tissue by air freight within Australia may be warranted.

are located in Brisbane, Sydney, Melbourne, Adelaide and Perth. The banks request consent for corneal donation and subsequently retrieve, evaluate, preserve and distribute human corneas for transplantation.

The Australian Corneal Graft Registry follows the progress of all corneal grafts performed in Australia. Established in May 1985, it collects information on recipients, donors, eye bank practices, surgical procedure, subsequent management, complications, graft survival, and visual outcomes after the graft. Yearly follow-up is requested until graft failure, recipient death or loss to follow-up. Deidentified and amalgamated registry analyses are used to inform clinical practice and to identify risk factors for poor outcomes. The registry's operations are approved by the Southern Adelaide Clinical Human Research Ethics Committee and are carried out in accordance with the Declaration of Helsinki.

At the census date for this study (July 2012), 24984 corneal grafts had been registered (Box 1). We analysed data for penetrating (full-thickness) and lamellar (partial-thickness) grafts, but not limbal (stem cell) grafts.
Lamellar grafts were further categorised into traditional (peripheral or patch) lamellar, deep anterior lamellar and endothelial keratoplasty. Methods of data collection have been published elsewhere. ${ }^{7}$

\section{Statistical analysis}

To identify potential risk factors for graft failure, we performed univariate analysis for 19254 corneal grafts in 15160 patients for which at least one follow-up had been recorded by the census date ("followed grafts"). Graft failure was reported by follow-up surgeons when the graft was no longer achieving the function for which it was performed (eg, functional vision). We examined the distribution across variables for grafts that had been followed and those that had not, to determine potential biases in the study population.

We performed Kaplan-Meier survival analysis ${ }^{8}$ using SPPS version 18 (SPSS Inc), with significance set at $P<0.05$ (Mantel-Cox log-rank $\chi^{2}$ statistic), to examine the influence of: time from death to enucleation $(\leqslant 3$ hours, 4-6 hours, 7-9 hours, 10-12 hours, $>12$ hours); time from death to storage ( $\leqslant 6$ hours, $7-12$ hours, $13-18$ 
1 Numbers of patients and corneal grafts registered and followed, by graft type

Patients

Grafts

\begin{tabular}{|c|c|c|c|c|c|c|c|c|c|c|c|}
\hline Graft type & Registered & Followed & Registered & $\begin{array}{l}\text { Lost before } \\
\text { follow-up }\end{array}$ & Followed & Failed* & $\begin{array}{l}\text { Recipient } \\
\text { has died }\end{array}$ & $\begin{array}{l}\text { Lost after } \\
\text { follow-up }\end{array}$ & $\begin{array}{l}\text { Still being } \\
\text { followed }\end{array}$ & $\begin{array}{l}\text { Not yet } \\
\text { followed }\end{array}$ & $\begin{array}{l}\text { Still active } \\
\text { in registry }\end{array}$ \\
\hline Penetrating & 16491 & $\begin{array}{c}13673 \\
(82.91 \%)\end{array}$ & 21303 & $\begin{array}{c}1896 \\
(8.90 \%)\end{array}$ & $\begin{array}{c}17301 \\
(81.21 \%)\end{array}$ & $\begin{array}{c}4173 \\
(19.59 \%)\end{array}$ & $\begin{array}{c}4896 \\
(22.98 \%)\end{array}$ & $\begin{array}{c}6142 \\
(28.83 \%)\end{array}$ & $\begin{array}{c}3337 \\
(15.66 \%)\end{array}$ & $\begin{array}{c}2106 \\
(9.89 \%)\end{array}$ & $\begin{array}{c}5443 \\
(25.55 \%)\end{array}$ \\
\hline \multicolumn{12}{|l|}{ Lamellar } \\
\hline Endothelial & 1415 & $\begin{array}{c}644 \\
(45.51 \%)\end{array}$ & 1697 & $\begin{array}{c}47 \\
(2.76 \%)\end{array}$ & $\begin{array}{c}738 \\
(43.49 \%)\end{array}$ & $\begin{array}{c}216 \\
(12.73 \%)\end{array}$ & $\begin{array}{c}28 \\
(1.65 \%)\end{array}$ & $\begin{array}{c}48 \\
(2.83 \%)\end{array}$ & $\begin{array}{c}451 \\
(26.58 \%)\end{array}$ & $\begin{array}{c}912 \\
(53.74 \%)\end{array}$ & $\begin{array}{c}1363 \\
(80.32 \%)\end{array}$ \\
\hline $\begin{array}{l}\text { Traditional } \\
\text { lamellar }^{\dagger}\end{array}$ & 1083 & $\begin{array}{c}857 \\
(79.13 \%)\end{array}$ & 1191 & $\begin{array}{c}161 \\
(13.52 \%)\end{array}$ & $\begin{array}{c}939 \\
(78.84 \%)\end{array}$ & $\begin{array}{c}223 \\
(18.72 \%)\end{array}$ & $\begin{array}{c}265 \\
(22.25 \%)\end{array}$ & $\begin{array}{c}390 \\
(32.75 \%)\end{array}$ & $\begin{array}{c}121 \\
(10.16 \%)\end{array}$ & $\begin{array}{c}91 \\
(7.94 \%)\end{array}$ & $\begin{array}{c}212 \\
(17.80 \%)\end{array}$ \\
\hline $\begin{array}{l}\text { Deep anterior } \\
\text { lamellar }\end{array}$ & 639 & $\begin{array}{c}273 \\
(42.72 \%)\end{array}$ & 677 & $\begin{array}{c}94 \\
(13.88 \%)\end{array}$ & $\begin{array}{c}276 \\
(40.77 \%)\end{array}$ & $\begin{array}{c}30 \\
(4.43 \%)\end{array}$ & $\begin{array}{c}4 \\
(0.59 \%)\end{array}$ & $\begin{array}{c}58 \\
(8.57 \%)\end{array}$ & $\begin{array}{c}186 \\
(27.47 \%)\end{array}$ & $\begin{array}{c}307 \\
(45.35 \%)\end{array}$ & $\begin{array}{c}493 \\
(72.82 \%)\end{array}$ \\
\hline $\begin{array}{l}\text { Limbal (not } \\
\text { analysed) }\end{array}$ & 104 & $\begin{array}{c}88 \\
(84.61 \%)\end{array}$ & 116 & $\begin{array}{c}10 \\
(8.62 \%)\end{array}$ & $\begin{array}{c}98 \\
(84.48 \%)\end{array}$ & $\begin{array}{c}47 \\
(40.52 \%)\end{array}$ & $\begin{array}{c}26 \\
(22.41 \%)\end{array}$ & $\begin{array}{c}28 \\
(24.14 \%)\end{array}$ & $\begin{array}{c}6 \\
(5.17 \%)\end{array}$ & $\begin{array}{c}8 \\
(6.90 \%)\end{array}$ & $\begin{array}{c}14 \\
(12.07 \%)\end{array}$ \\
\hline Total in registry & 19163 & $\begin{array}{c}15248 \\
(79.57 \%)\end{array}$ & 24984 & $\begin{array}{c}2208 \\
(8.84 \%)\end{array}$ & $\begin{array}{c}19352 \\
(77.46 \%)\end{array}$ & $\begin{array}{c}4689 \\
(18.77 \%)\end{array}$ & $\begin{array}{c}5219 \\
(20.89 \%)\end{array}$ & $\begin{array}{c}6666 \\
(26.68 \%)\end{array}$ & $\begin{array}{c}4101 \\
(16.41 \%)\end{array}$ & $\begin{array}{c}3424 \\
(13.70 \%)\end{array}$ & $\begin{array}{c}7525 \\
(30.12 \%)\end{array}$ \\
\hline Total analysed & 19059 & $\begin{array}{c}15160 \\
(79.54 \%)\end{array}$ & 24868 & $\begin{array}{c}2198 \\
(8.84 \%)\end{array}$ & $\begin{array}{c}19254 \\
(77.42 \%)\end{array}$ & $\begin{array}{c}4642 \\
(18.67 \%)\end{array}$ & $\begin{array}{c}5193 \\
(20.88 \%)\end{array}$ & $\begin{array}{c}6638 \\
(26.69 \%)\end{array}$ & $\begin{array}{c}4095 \\
(16.47 \%)\end{array}$ & $\begin{array}{c}3416 \\
(13.74 \%)\end{array}$ & $\begin{array}{c}7511 \\
(30.20 \%)\end{array}$ \\
\hline
\end{tabular}

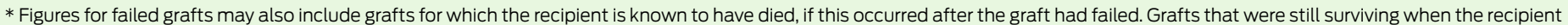
died are not treated as failed grafts but rather censored at the time of death. $†$ Peripheral or patch.

hours, 19-24 hours, $>24$ hours); time from enucleation to graft $(\leqslant 48$ hours, 49-96 hours, 97-144 hours, >144 hours); storage method used (Optisol [Bausch and Lomb], organ culture, moist pot, superseded media); and whether or not the cornea had been transported interstate by air. Superseded media included McCareyKaufman medium, K-Sol (Bausch and Lomb) and Dexsol (Bausch and Lomb). Where fewer than 20 grafts were followed for a variable (Appendix 1; online at mja.com.au), these grafts were excluded from analyses relating to the variable for that type of graft. For variables with just two groups, univariate analyses were not conducted if one group had insufficient numbers. No other exclusions were applied.

Indication for corneal transplantation has previously been found to be a highly significant predictor of graft survival in the registry, ${ }^{9}$ with keratoplasties performed for keratoconus exhibiting good survival rates compared with all other indications. Furthermore, although most corneal grafts performed in Australia are elective, a small proportion are performed on an emergency basis (eg, for a penetrating eye injury or herpetic perforation) and such grafts tend to be at high risk of subsequent failure. ${ }^{9}$ We therefore considered that indication for graft (emergency, keratoconus or other) might be a confounder in our analysis, particularly as corneas transported by air and those stored in moist pots in recent years are more likely to have been used in emergency procedures. Where appropriate, we examined the effect that graft era (1985-1995 v 1996 onwards) may have on survival,
2 Main indication for followed grafts as specified by surgeon, by graft type $(n=19254)$

\begin{tabular}{lcccc} 
Main indication for graft & Penetrating & Traditional lamellar & Deep anterior lamellar & Endothelial \\
\hline Keratoconus & $5213(30.13 \%)$ & $70(7.45 \%)$ & $199(72.10 \%)$ & 0 \\
Bullous keratopathy & $3935(22.74 \%)$ & $11(1.17 \%)$ & 0 & $215(29.13 \%)$ \\
Failed previous graft & $3585(20.72 \%)$ & $141(15.02 \%)$ & $6(2.17 \%)$ & $136(18.43 \%)$ \\
Corneal dystrophies & $1900(10.98 \%)$ & $13(1.38 \%)$ & $6(2.17 \%)$ & $365(49.46 \%)$ \\
Corneal scars and opacities & $391(2.26 \%)$ & $28(2.98 \%)$ & $6(2.17 \%)$ & 0 \\
Non-herpetic corneal ulcers & $338(1.95 \%)$ & $121(12.89 \%)$ & $2(0.72 \%)$ & 0 \\
Herpetic eye disease & $738(4.27 \%)$ & $37(3.94 \%)$ & $18(6.52 \%)$ & $1(0.14 \%)$ \\
Accidental injury & $395(2.28 \%)$ & $118(12.57 \%)$ & $7(2.54 \%)$ & $13(1.76 \%)$ \\
Other* & $806(4.66 \%)$ & $400(42.60 \%)$ & $32(11.59 \%)$ & $8(1.08 \%)$ \\
Total & 17301 & 939 & 276 & 738
\end{tabular}

* For example: corneal degenerations, congenital abnormalities, descemetoceles, iridocorneal endothelial syndrome, metabolic deposits. as eye banking techniques have changed over time.

We conducted multivariate Cox proportional hazards regression analyses $^{10,11}$ using Stata version 11 (StataCorp) to determine independent risk factors for survival of each type of graft. As some patients had received more than one graft, the data were clustered by recipient, using the Breslow method for ties, to control for intergraft or intereye dependence. ${ }^{12}$ Analyses were performed in a backwards stepwise manner, initially including all variables found to be significant in the univariate analysis. Where appropriate, variables were treated as time-variant. The least significantly contributing variable was removed until all variables made a significant $(P<0.05)$ independent contribution to the model. Some follow-up records were missing data for one or more of the variables of interest. At each stage of the regression, records with complete data for all of the included variables were analysed. Hazard ratios (HRs), adjusted for clustering and the impact of other variables in the model, were used to compare survival across categorical variables. The first level of each variable was used as the referent.

\section{Results}

Eye bank practices for followed and not-yet-followed grafts are reported in Appendix 2 (online at mja.com.au). Equivalent proportions of corneas in 
each cohort had been transported by air freight. There were similar distributions of indications for grafts across the two groups. For followed grafts, the main indications for each type of graft are shown in Box 2.

Univariate analyses of survival for each type of graft, stratified by eye bank variable, are shown in Box 3. Storage method significantly influenced survival of traditional lamellar and endothelial grafts $(P<0.001)$. For endothelial grafts, corneas stored in organ culture fared significantly worse than those stored in Optisol (Box 4). Interstate air freight transportation of the donor cornea affected survival of penetrating grafts and traditional lamellar grafts $(P<0.001)$ (Box 3 and Box 5). Death-to-enucleation time exerted a significant influence on the survival of deep anterior lamellar grafts (Box 6) and penetrating grafts, and enucleation-to-graft time also significantly affected the survival of penetrating grafts (Box 3). Death-tostorage time exerted no significant influence on graft survival. Indication for the graft had a significant impact on survival for penetrating and traditional lamellar grafts, and graft era significantly affected survival of traditional lamellar grafts (all $P<0.001$ ).

In the multivariate model (Box 7), interstate transportation by air freight and indication for graft were significant contributors to outcomes of penetrating grafts $\left(\chi^{2}=7863.75\right.$, $P<0.001)$. These variables, along with storage method, were also significant contributors to outcomes of

\begin{tabular}{|c|c|c|c|c|c|c|c|c|}
\hline \multirow[b]{2}{*}{ Variable } & \multicolumn{2}{|c|}{ Penetrating } & \multicolumn{2}{|c|}{ Traditional lamellar } & \multicolumn{2}{|c|}{ Deep anterior lamellar } & \multicolumn{2}{|c|}{ Endothelial } \\
\hline & $\chi^{2}$ & $P$ & $\chi^{2}$ & $P$ & $\chi^{2}$ & $P$ & $\chi^{2}$ & $P$ \\
\hline Storage method & 6.25 & 0.10 & 19.71 & $<0.001$ & 0.81 & 0.37 & 20.67 & $<0.001$ \\
\hline Transport by air freight & 23.19 & $<0.001$ & 13.73 & $<0.001$ & na & na & 1.44 & 0.23 \\
\hline Death-to-enucleation time & 9.91 & 0.04 & 1.56 & 0.82 & 10.67 & 0.03 & 7.87 & 0.10 \\
\hline Death-to-storage time & 3.85 & 0.43 & 1.03 & 0.91 & 4.92 & 0.30 & 5.24 & 0.26 \\
\hline Enucleation-to-graft time & 9.06 & 0.03 & 1.85 & 0.60 & 2.57 & 0.46 & 0.81 & 0.85 \\
\hline Indication for graft & 1597.95 & $<0.001$ & 49.42 & $<0.001$ & 3.62 & 0.16 & na & na \\
\hline Graft era & 1.31 & 0.25 & 7.37 & $<0.001$ & na & na & na & na \\
\hline
\end{tabular}

traditional lamellar grafts $\left(\chi^{2}=65.51\right.$, $P<0.001)$. For both penetrating and traditional lamellar grafts, transport of the donor cornea by air freight and high-risk indication for the graft were significant risk factors for failure. Penetrating grafts performed for keratoconus had significantly better survival than those performed for other indications, but this was not the case for traditional lamellar grafts. For traditional lamellar grafts, corneas that had been stored in moist pots fared better than did those stored in Optisol.

\section{Discussion}

Unlike many other factors that are known to influence corneal graft survival, eye banking practices are amenable to change. In line with previous reports, we found that, once the influence of other significant variables was taken into account, donor death-toenucleation time, enucleation-to-

5 Kaplan-Meier plot of survival of penetrating grafts (A) and traditional lamellar grafts (B) performed with donor corneas transported by air compared with those retrieved and used locally*
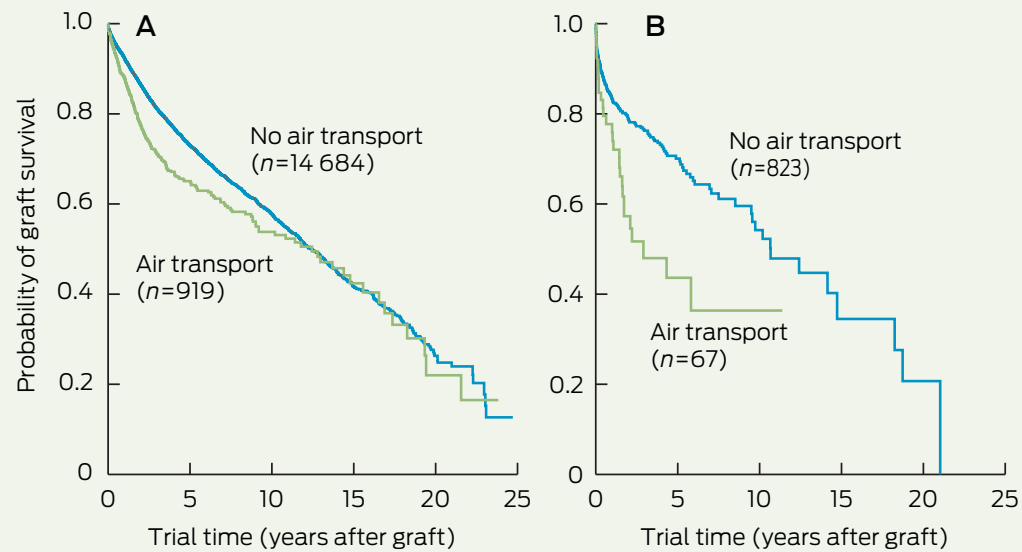

No air transport = corneas retrieved and used within the same state. Air transport = cornea retrieved in one state and transported by air freight for use in a different state. ${ }^{*} P<0.001$, Peto log-rank statistic.

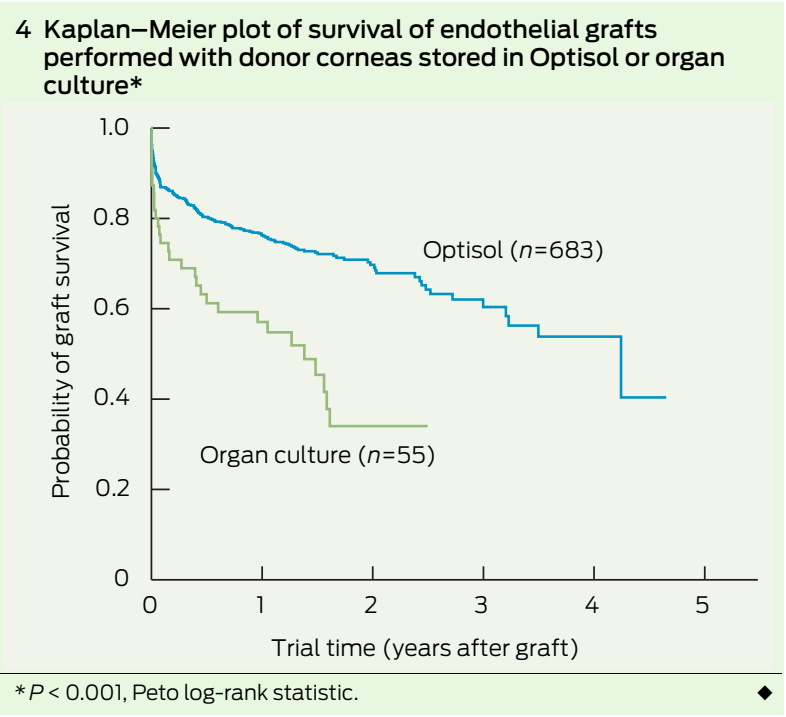

graft time, and storage time of a cornea in the eye bank did not exert a significant influence on the probability of graft survival for most graft types. While a significant effect of death-to-enucleation time on survival of deep anterior lamellar grafts was found, no specific relationship between the two that could inform best practice was apparent. Most analysed grafts were conducted with donor tissue that was retrieved, stored and transplanted within nationally recommended time frames. ${ }^{13}$ Our findings add to the evidence that operating within these guidelines protects corneal donor tissue from detrimental postmortem changes.

For some graft types, we found that the method of cornea preservation influenced subsequent corneal graft survival. Optisol, a tissue culture medium to which antibiotics, dehydrating agents, ATP precursors and vitamins have been added, is one of the latest alternative cold-storage techniques. ${ }^{1,14,15}$ It gradually replaced 
6 Kaplan-Meier plot of survival of deep anterior lamellar grafts performed with donor corneas enucleated at various times after donor death*

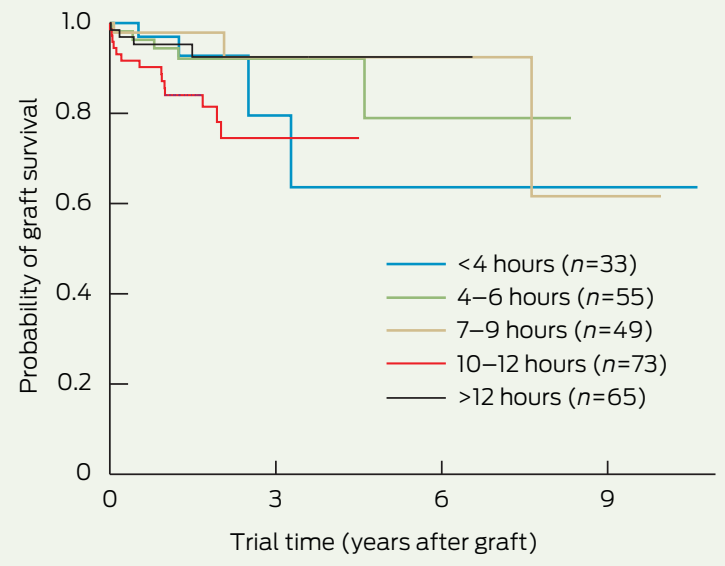

*P=0.031, Peto log-rank statistic.

other now superseded media in Australia over about 10 years from 1990 . Corneas are stored in Optisol at $4^{\circ} \mathrm{C}$ for a recommended maximum of 14 days. ${ }^{16}$ Moist pot storage ${ }^{1,17}$ involves the entire eye being placed in a container kept at $4^{\circ} \mathrm{C}$. It is limited by rapid deterioration in the viability of the cornea after $24-48$ hours $^{18}$ and is now seldom used. In recent years, there has been a shift in some parts of Australia towards preserving donor corneas in organ culture, as is the practice in Europe. ${ }^{14,17}$ Corneas are stored at $30-37^{\circ} \mathrm{C}$, with bovine calf serum and antibiotics including antifungal agents added to the tissue culture medium, for up to 4 weeks. ${ }^{14,19}$ This shift was reflected in the grafts registered at the time of this study, with $9 \%$ and $87 \%$ of all grafts performed from 2000 onwards using corneas stored in organ culture and Optisol, respectively, compared with $26 \%$ and $72 \%$, respectively, for grafts performed from only 2010 onwards (data not shown).

In confirmation of previous studies, we found no significant difference in penetrating graft survival between corneas stored in Optisol or organ culture. ${ }^{5,15,16}$ Corneas used for traditional lamellar procedures exhibited significantly better survival when stored in moist pots than in Optisol. We speculate that the greater swelling of the corneal stroma that occurs in Optisol-stored corneas may render wound apposition during lamellar surgery more difficult. This suggests that different storage techniques may be warranted, depending on graft technique. The small number of traditional lamellar grafts being performed these days and the reduced length of viability for corneas stored in moist pots mean that this finding is unlikely to influence clinical practice.

\section{Multivariate analysis for influence of corneal transport and storage and indication for graft on corneal graft survival, for penetrating and traditional lamellar grafts}

\begin{tabular}{|c|c|c|c|c|}
\hline Variable & Number of grafts & Hazard ratio $(95 \% \mathrm{Cl})$ & $P$ & Global $P$ \\
\hline \multicolumn{5}{|l|}{ Penetrating grafts } \\
\hline \multicolumn{5}{|l|}{ Transported by air freight* } \\
\hline No & 14684 & 1.00 & & \\
\hline Yes & 919 & $1.44(1.21-1.73)$ & 0.001 & \\
\hline \multicolumn{5}{|l|}{ Indication for graft* } \\
\hline Not keratoconus or high-risk & 10265 & 1.00 & & $<0.001$ \\
\hline Keratoconus & 4611 & $0.16(0.13-0.19)$ & $<0.001$ & \\
\hline High-risk indication ${ }^{\dagger}$ & 727 & $2.53(2.10-3.04)$ & $<0.001$ & \\
\hline \multicolumn{5}{|l|}{ Traditional lamellar grafts } \\
\hline \multicolumn{5}{|l|}{ Transported by air freight } \\
\hline No & 813 & 1.00 & & \\
\hline Yes & 64 & $1.69(1.03-2.78)$ & 0.038 & \\
\hline \multicolumn{5}{|l|}{ Storage media } \\
\hline Optisol & 233 & 1.00 & & 0.047 \\
\hline Moist pot & 480 & $0.61(0.41-0.91)$ & 0.016 & \\
\hline Superseded media & 164 & $0.63(0.39-1.02)$ & 0.059 & \\
\hline \multicolumn{5}{|l|}{ Indication for graft* } \\
\hline Not keratoconus or high-risk & 600 & 1.00 & & $<0.001$ \\
\hline Keratoconus & 65 & $0.66(0.32-1.33)$ & 0.247 & \\
\hline High-risk indication ${ }^{\dagger}$ & 212 & $3.15(2.16-4.61)$ & $<0.001$ & \\
\hline
\end{tabular}

*Analyses adjusted for interaction with time for both variables in the penetrating graft model and for indication for graft in the traditional lamellar graft model. $\dagger$ Includes endophthalmitis, corneal melt, perforation, trauma or accidental injury, and burn, sometimes in combination with another indication.

Our finding that for endothelial grafts, corneas stored in organ culture fared worse than those stored in Optisol may suggest a negative impact of organ culture preservation on endothelial cell viability. However, a similar difference was not found for penetrating grafts, which also involve the endothelial layer. Possibly there are other variables not related to the eye bank that are influencing this result, and further exploration is warranted. Overall, the choice of corneal storage medium may affect graft survival, and this effect appears to vary for different types of keratoplasty.

A significant difference was apparent between the outcomes of grafts involving corneas that had been sent interstate by air compared with those retrieved and used locally. Transport of donor corneas by air within Australia was associated with poorer survival of penetrating and traditional lamellar grafts, and the HRs indicated a clinically important impact. Furthermore, the multivariate model also included recipient indication for graft, which shows that differences in survival cannot be explained by transported corneas being used more often in emergency procedures. For penetrating grafts, this effect varied over time: there was an initial reduction in survival, but equivalent levels were seen after the first 12 years, with equal median survival.

The impact of international air travel on the outcomes of penetrating keratoplasty has been reported previously. 4,6,20 One study examined the changes in corneal endothelial cell morphology that occurred in corneas between leaving the United States and arriving in Taiwan, and evaluated outcomes achieved after transplantation of these corneas. ${ }^{4}$ Obvious transport-related morphological changes were observed and by 4 years after the graft, nearly half the grafts had failed. Despite this, the authors concluded that the surgical success rate was not influenced by the air transport. With no comparison group, it cannot be determined whether this failure rate was unusual. A second study, from Israel, evaluated the outcomes of grafts involving local donors and those for which corneas were procured from the US. ${ }^{6}$ The authors concluded that air transport had not compromised the success of the cor- 
neal transplants. In a third study, no significant differences in the likelihood of survival, primary graft failure, rejection or infection were found between corneas imported from the US and those sourced locally in Japan. ${ }^{20}$ All these studies were small, with limited follow-up periods.

Our finding that air transport of stored donor corneas was associated with reduced corneal graft survival was unexpected. Nevertheless, given the size of the dataset, the inclusion of data from multiple eye banks working within the same guidelines, and the extended follow-up available for penetrating and traditional lamellar grafts, we consider the result to be robust. So what might be the cause of the deleterious influence of air transport within Australia on human donor corneas? Australian eye banks have undertaken validation of temperature control in shipping containers under various simulated and actual conditions, and report that temperature fluctuations are small. Shaking, pressure changes, and rapid acceleration and deceleration may play a role. ${ }^{4,5,21,22}$ Although our study has identified an association between air freight of donor corneas and subsequent poor outcomes after transplantation, we cannot identify the cause. Further modification of corneal transport containers is difficult without a clearer understanding of the underlying cause of the problem.

Our findings highlight the need for continued evaluation of the impact of eye bank practices on corneal graft survival. Transportation of donor corneas around the world has increased in recent years, as some countries retrieve more corneas than others. A balance needs to be struck between duplication of services with attendant additional expense, appropriate use of a scarce human resource so that wastage is minimised, and the needs of recipients and their surgeons. Air freight of some corneas will always be necessary. However, in Australia, where sufficient donor tissue is generally available within each state, efforts to avoid domestic air transportation of corneal tissue may be warranted. Furthermore, we suggest that centralisation of donor cornea retrieval services may not be in the best interests of the community, at least until the transport of human donor corneas can be improved.

Acknowledgements: We thank Victoria Jones for data entry and validation. We appreciate the voluntary contribution of information by over 700 Australian ophthalmologists and all Australian eye banks. The Australian Corneal Graft Registry is supported by the Australian Organ and Tissue Donation and

Transplantation Authority (DonateLife). Keryn Williams is supported by the National Health and Medical Research Council.

Competing interests: Graeme Pollock is the Director of the Lions Eye Donation Service in Victoria and thus performs the corneal collection, preservation and distribution practices outlined in this study for corneas donated in Victoria.

Received 24 Oct 2012, accepted 11 Jun 2013.

1 Pels E, Beele H, Claerhout I. Eye bank issues: II. Preservation techniques: warm versus cold storage. Int Ophthalmol 2008; 28: 155-163.

2 Kryczka T, Szaflik J, Szaflik J, Midelfart A. Influence of donor age, post-mortem time and cold storage on metabolic profile of human cornea. Acta Ophthalmol 2013; 91: 83-87.

3 Thuret G, Chiquet C, Bernal F, et al. Prospective, randomized clinical and endothelial evaluation of 2 storage times for corneal donor tissue in organ culture at 31 degrees C. Arch Ophthalmol 2003; 121: 442-450.

4 Hu FR, Tsai AC, Wang IJ, Chang SW. Outcomes of penetrating keratoplasty with imported donor corneas. Cornea 1999; 18: 182-187.

5 Halberstadt M, Athmann S, Winter R, Hagenah M. Impact of transportation on short-term preserved corneas preserved in Optisol-GS, Likorol, Likorol-DX, and MK-medium. Cornea 2000; 19: 788-791.

6 Varssano D, Russ V, Linhart Y, Lazar M. Air transportation of corneal tissue: experience with local compared to transatlantic donor corneas. Cornea 2005: 24: 674-677.
7 Lowe MT, Keane MC, Coster DJ, Williams KA. The outcome of corneal transplantation in infants, children, and adolescents. Ophthalmology 2011; 118: 492-497.

8 Kaplan E, Meier P. Nonparametric estimation from incomplete observations. J Am Stat Assoc 1958; 53: 475-481.

9 Williams KA, Lowe M, Bartlett C, et al. Risk factors for human corneal graft failure within the Australian corneal graft registry. Transplantation 2008; 86: 1720-1724.

10 Peto R, Pike MC, Armitage P, et al. Design and analysis of randomized clinical trials requiring prolonged observation of each patient. I. Introduction and design. Br J Cancer 1976; 34 : 585-612.

11 Peto R, Pike MC, Armitage P, et al. Design and analysis of randomized clinical trials requiring prolonged observation of each patient. II. Analysis and examples. Br J Cancer 1977; 35: 1-39.

12 Williams RL. A note on robust variance estimation for cluster-correlated data. Biometrics 2000; 56: 645-646.

13 Eye Bank Association of Australia and New Zealand. EBAANZ medical and quality standards for eye donation and eye tissue banking. 2nd ed. April 2009. http://www.ebaanz.org/quality_ standards_28.html (accessed Oct 2012).

14 Pels L. Organ culture: the method of choice for preservation of human donor corneas. $\mathrm{Br} \mathrm{J}$ Ophthalmol 1997; 81: 523-525.

15 Frueh BE, Böhnke M. Prospective, randomized clinical evaluation of Optisol vs organ culture corneal storage media. Arch Ophthalmol 2000; 118: 757-760.

16 Wagoner MD, Gonnah el-S. Corneal graft survival after prolonged storage in Optisol-GS. Cornea 2005; 24: 976-979.

17 Ehlers N. Corneal banking and grafting: the background to the Danish Eye Bank System, where corneas await their patients. Acta Ophthalmol Scand 2002; 80: 572-578.

18 Wilson SE, Bourne WM. Corneal preservation. Surv Ophthalmol 1989; 33: 237-259.

19 Pels E, Rijneveld WJ. Organ culture preservation for corneal tissue. Technical and quality aspects. Dev Ophthalmol 2009; 43: 31-46.

20 Shimazaki J, Shinozaki N, Shimmura S, et al. Efficacy and safety of international donor sharing: a single-centre, case-controlled study on corneal transplantation. Transplantation 2004; 78: 216-220.

21 Tauber S, Bowman J, Bango J, Fuerst R. Precise temperature control of donor cornea tissue with reusable passibe thermal container. Cornea 2011; 30: 977-982.

22 Wang IJ, Hu FR. Effect of shaking on corneal endothelial preservation. Curr Eye Res 1997; 16: 1111-1118. 